\title{
Compounds, creativity and complexity in climate change communication: The case of 'carbon indulgences'
}

\begin{abstract}
This article deals with climate change from a linguistic perspective. Climate change is an extremely complex issue that has exercised the minds of experts and policy makers with renewed urgency in recent years. It has prompted an explosion of writing in the media, on the internet and in the domain of popular science and literature, as well as a proliferation of new compounds around the word 'carbon' as a hub, such as 'carbon indulgence', a new compound that will be studied in this article. Through a linguistic analysis of lexical and discourse formations around such 'carbon compounds' we aim to contribute to a broader understanding of the meaning of climate change. Carbon compounds are used here as indicators for observing how human symbolic cultures change and adapt in response to environmental threats and how symbolic innovation and transmission occurs.
\end{abstract}

Keywords: climate change, discourse analysis, compounds, metaphors, linguistic creativity, ecolinguistics

\section{Introduction}

Climate change is a complex problem that demands collective solutions. Finding such solutions is problematic, as we are dealing with is an example of a so-called 'wicked' policy problem (Hulme, 2008b). Interestingly, since the turn of the millennium this problem has produced a novel collective and linguistic response that is interesting for several reasons. 
Public controversies, most importantly around biotechnology, but more recently around climate change, have attracted large amounts of attention from social scientists. Much of this research has focused on the invention and spread of metaphors and other framing devices in media, policy and practitioner discourses (see e.g. Weingart et al., 2000, Boykoff, 2008, Carvalho, 2007, Alexander, 2008). As Mike Hulme has recently pointed out:

\footnotetext{
Just as the physical climate-system responds both to slow-changing natural rhythms and also to more rapid human-induced perturbations, so will those human artefacts we use to make sense of climate change - language, metaphors, policies, beliefs - respond both rapidly and slowly to the new financial and economic mood. (Hulme, 2008a)
}

In this context attention should be paid to collective processes of sense-making, which are more hidden but no less important than metaphors, such as the repeated and prolific use of compounding, a rather run-of-the mill linguistic procedure used to form new words by combining or putting together old words. We shall focus here on what we call 'carbon compounds', that is lexical compounds around 'carbon' as a hub.

A good example of a novel compound is 'carbon footprint'. Advice on how to reduce one's 'carbon footprint' as part of attempts to mitigate the effects of climate change is provided almost daily in the media, by NGOs and by governments. Other examples of 'carbon compounds' are 'carbon finance', 'carbon sinner', or a 'low carbon diet'. These are only some of the numerous lexical and metaphorical clusters that have emerged recently. A whole new language is evolving that needs to be monitored and investigated in order to discover how climate change is made sense of by various 
stakeholders, how public attitudes and perceptions are shaped and what solutions to climate change and global warming are proposed. Mapping the emergence and rhetorical use of carbon compounds might provide insights into changing trends in public perception of and attitudes to climate change. The focus is here on understanding one part of the symbolic culture on which such perceptions and attitudes may rest.

Compounds may be much less spectacular than some of the metaphors that have been used to structure public debates in the past (although, as we shall see, some compounds are also metaphors), but in the case of climate change they have emerged as a framing device that fits well the complexity of the issue itself. Although compounds may seem trivial in themselves, en masse they structure some aspects of English climate change discourse in intriguing ways. They have recently exploded on the English linguistic scene. This 'carbon explosion' can be compared to the 'Cambrian explosion' -the seemingly sudden appearance of a variety of complex animals about 540 million years ago. This explosion was for example signalled by lexicographers when The New Oxford American Dictionary' declared 'carbon neutral' Word of the Year for 2006 (see: http://blog.oup.com/2006/11/carbon_neutral; for more information about this lexical explosion, see section 3).

This article aims to provide an overview of this discursive explosion of 'carbon compounds' and then to home in on one intriguing example of a creative and semantically complex carbon compound ('carbon indulgence') to examine how it functions inside climate change discourse. Over and above providing insights into the linguistic structuring of climate change communication, studying the emergence and spread of carbon compounds may also provide new insights into patterns of collective linguistic and epistemic creativity which - as Victor Klemperer has shown in his analysis of Nazi lexis (1947) - works in an invisible but very effective way. 


\section{Method and conceptual framework}

Most linguists regard 'linguistic creativity' as the human skill to combine known words in new sentences or to express thoughts in figurative language. It is normally seen as being located within the individual rather than the collective (for a critical review of the concept see Zawada, 2006).

Here we argue that creativity can also be a collective phenomenon, more particularly we see it as a result of what Rudi Keller called the 'invisible hand' process which underlies the emergence of macro-level features from micro-level actions (see Keller, 1989). In our case, the increasing use, diversification and spread of carbon compounds can be seen as "the unintended cumulative consequence of a countless number of intentional communicative acts by countless people” (Keller, 1989, p. 115), where the intentional communicative acts are carried out by scientists, governments, PR companies, the media, NGOs and so on. The invisible hand process links such individual creativity to emergent collective complexity.

In some way, carbon compounds, once invented as a linguistic framing device in debates about climate change in the English speaking world, behaved in some way like popular metaphors that once invented spread throughout the public domain and structure debates about particular controversies. They are repeated and varied; they are selected and rejected; some become models for further selection and repetition; some items and some models increase in frequency, others vanish; in short; they evolve. They also form interesting networks, both lexical and discursive ones, as well as epistemic ones. By spinning an every more complex conceptual web, they make us see and understand climate change in different ways and perhaps also make us behave differently in response to its threats. 
In his book Frankenstein's Footsteps Jon Turney (1998) suggested that just the title of a cultural reference, such as Frankenstein, can evoke an entire story or 'script', which can be used again and again as an interpretative frame by journalists, policy makers or activists to get to grips with an issue or controversy. This frame then structures the narratives through which the media communicate concerns, for example about cloning or stem cells. The blend Frankenfood, for example, which was invented in 1992, has spread far and wide and structured countless debates about genetically modified food, crops and organisms and contributed to the emergence of a 'genetically modified language' (Cook, 2004). One aspect of this spread has been studied in detail by Iina Hellsten in her article "Focus on Metaphors: The Case of 'Frankenfood' on The Web" (Hellsten, 2003).

The challenge we face in our research into the emergence of a 'carbon language' is to study the use and spread of a whole cohort of compounds. To make this task manageable for this article, we will only provide a brief overview of the emergence and spread of some carbon compounds in English, before narrowing down our research to one carbon compound, 'carbon indulgence', that structured one major controversy in debates about climate change mitigation, namely, carbon offsetting.

The conceptual framework within which we carry out this study is 'ecolinguistics' in general and what one might metaphorically call 'the ecology of compounds' in particular. Ecolinguistics emerged in the 1990s as a new paradigm of linguistic research which takes into account not only the social context in which language is embedded, but also the ecological context in which societies are embedded. It uses a variety of methods and approaches, such as discourse analysis and metaphor analysis (see e.g. Fill and Mühlhäusler, 2001). Ecolinguists have so far not studied the influence of compounds on environmental discourses or the influence of environmental issues on the emergence of 
new compounds (but see Gerbig, 1996 for a study of collocational patterns in the Ozone debate). We advocate here an ecological study of compounds as part of ecolinguistics.

Evolutionary ecology studies how organisms evolve and adapt in interaction with their environments, or more radically, how organisms co-evolve with their environments. The evolutionary ecology of compounds would similarly study how such linguistic devices emerge, get adopted and adapted, change and co-evolve in contextual use. Their study would provide some initial insights into the adaptability of language as part of symbolic culture to new environmental challenges.

Compounds are linguistic signs and as such they "are both transformative cognitive tools and constitutive of specifically human cultural ecologies" (Sinha, 2006: 114) or biocultural niches. Carbon compounds, such as 'carbon footprint', create ways of making sense of our surroundings, a new understanding that can also influence how we act upon it. Over and above their intrinsic semantics they therefore also have a 'pragmatic', dynamic, action-oriented face and might aid in the mobilisation of human beings behind environmental causes or indeed in turning them away from them.

Compounds have troubled linguists for a long time. Noun-noun compounds are especially reticent to theorisation. "Headache pills demolish headaches, fertility pills produce fertility and heart pills aid the heart. Moreover, slug powder kills slugs, talcum powder is made of purified talc and face powder goes on faces." (Aitchison, 1993, p. 154) The combinatorial and inferential possibilities seem endless. To create and understand such constructions speakers and hearers rely on semantic knowledge of the components, world knowledge and discourse knowledge (Meyer, 1993, p. 7). We shall illustrate how these types of knowledge interact by studying one compound that became ambiguous over time and then synonymous with another compound, a process that was clearly triggered by various events in the world and in discourse. We shall model our work on 
that carried out in the field of social semiotics. In Talking Science (1990), Lemke for example advocated the study of broader discourse formations - particular, recognizable combination of thematics, genre, and stylistic choices of rhetorical strategies and wordchoices, to which we want to add compounds.

We shall now provide a rough overview of the behaviour of some species of compounds from highly conventionalised and widespread ones, to more local ones adapted to more specialised discursive environments or niches and home in on one compound that will be studied in more detail within its surrounding discourses and events in the real world. At the same time this section will function as a justification of the corpora we chose to study discourse formations around 'carbon indulgence'.

\section{Compounds and corpus choice}

Some carbon compounds are quite old, such as the original carbon compound 'carbon dioxide' (1867, according to the OED); some are very new, such as 'carbon indulgence' (probably around 2000). In all carbon compounds we study 'carbon' is an ellipsis standing for 'carbon dioxide', as in 'carbon (dioxide) emissions' (on such 'incomplete compounds' see Warren, 1978). Some carbon compounds are used very frequently, such as 'carbon footprint', a creative metaphor that seems to have become the model for many other compound formations around carbon; some are creative one-offs, such as 'carbon cake' (on such so-called 'episodic' compounds, see Heringer, 1984, p. 9). Some carbon compounds have become lexically and morphologically productive, such as 'carbon footprint', which can be truncated to 'footprint', used as a verb as in 'footprinting', become part of other compounds, such as 'carbon footprinting system' and so on. Some, such as 'carbon cake', are quite inert and can only be used in a very limited contextual setting, such as 'have your carbon cake and eat it'. Some carbon compounds have become 
cornerstones of national and international climate change policies, such as 'carbon trading', some denote contested policy solutions, such as 'carbon tax'. Some are embedded in wider semantic fields or networks, such as the network surrounding 'carbon finance' (carbon trading, credits, tax, budget, accounts, years, management, fraud etc.); some are rooted in entrenched cultural narratives, such as dieting and weight loss, e.g. 'carbon diet' or 'low carbon diet', that is, they have not spawned a very wide-ranging network of compounds and derivations but a whole network of narratives and other compounds can resonate with this larger dietary frame, including, to some extent, our compound of choice, 'carbon indulgence'.

Obviously, many of these compounds are linked semantically and discursively, such that to (metaphorically) shrink ones 'carbon footprint' for example, one has to go (metaphorically) on a 'low-carbon diet' and avoid 'carbon indulgences' etc. Compounds can also function as tip-of-the-discursive-iceberg signals for a range of 'discourse formations'. Four larger discursive niches seem to be predominantly populated by carbon compounds: finance, science, lifestyle and attitude/evaluation. These discourses subsume compounds as well as metaphors and other framing devices. They form complex networks between themselves. And finally, some carbon compounds have changed their meaning over time or have developed multiple meanings, such as 'carbon storage', which, as the OED attests, was used in 1916 to indicate the amount of carbon that a bacterium can store as food, whereas now it has become part of the carbon compound phrase 'carbon capture and storage' referring to an approach aimed at mitigating global warming based on capturing carbon dioxide $\left(\mathrm{CO}_{2}\right)$ from fossil fuel power plants and storing it instead of releasing it into the atmosphere. 
Carbon compounds exploded onto the scene of climate change discourse in around 2004, see the following graph (Figure 1). ${ }^{1}$ The reasons for this 'carbon explosion' are not quite clear, but, according to our data, once carbon compounds started to proliferate, the rate of proliferation accelerated and creative uses increased, triggering dynamic feedback mechanisms. Again, linguists have debated the nature of creativity and productivity in compounds for a long time, a topic we shall leave aside in this article (but see Munat, 2007).

\section{[INSERT FIGURE 1 HERE]}

Some compounds, such as 'carbon footprint', went from 4 to 810 uses in UK newspapers between 2004 and 2006. Some compounds are used so frequently that they have entered the OED, e.g. 'carbon offset', 'carbon footprint', 'carbon trading', 'carbon credit', which

\footnotetext{
${ }^{1}$ To gain an initial indication of the number of newspaper articles using the word 'carbon' between 1980 and 2008 we carried out pilot searches in the Lexis Nexis database, the online information service which provides access to news worldwide. The wide search
} (All News, All Countries) generated a very large number of results which for most years exceeded 3,000 hits - the current retrieval limit for this database. We therefore limited our pilot search to one country, namely the UK, and mapped the number of both tabloid and broadsheet articles (that is 'national' newspapers) using the word 'carbon' since 1980s. As the figure shows, there has been a rapid increase in the number of articles around the year 2004, which was also the year we first started to notice and increase in the use of carbon compounds in general discourse. 
also demonstrates that the financial niche is well populated and its inhabitants are well entrenched in public discourse.

To narrow down the focus of this article we had to make a choice about which compounds or compound to study. One of the biggest compound clusters is that around carbon finance, as the following table shows. ${ }^{2}$

[INSERT FIGURE 2 HERE]

The use of 'carbon credits' and 'carbon offsetting' as financial mechanisms to mitigate climate change have been heatedly debated in the English speaking media. One part of the controversy surrounding carbon offsetting was indexed by one semantically multifaceted compound, 'carbon indulgence'. To study the use of this compound we will use two corpora. The first corpus is based on a Lexis Nexis search of 'All English language news' using the key word 'carbon indulgence' and consists of 33 articles. ${ }^{3}$ The second

${ }^{2}$ Figure 2 is part of a preliminary study of the use of 'carbon compounds' in UK national newspapers available via the Lexis Nexis database. This as yet unpublished study maps the use of all compounds headed by the word 'carbon' from the 1980-s onwards in the UK press. The results reveal a large number of 2- and 3- word compounds centred around four lexical sets: finance, science, lifestyle and attitude/evaluation.

${ }^{3}$ This corpus seems to be stable now. Between November 2008 when we started to write this article and February 2009 when we finalised revisions, there were no new articles written using 'carbon indulgence'. The peak of the carbon indulgence controversy therefore seems to have been around 2006 and 2007. It should be stressed however that 
corpus consists of 54 blog webpages generated by the WebCorp - a linguistic search engine designed to cache and process large sections of the web that was developed at Birmingham City University. We chose both more traditional news reports and blogs in order to gain deeper insight into the linguistic creativity and collective linguistic activity that structures the fast changing landscape of climate change discourse, where one can observe an explosion of information and debate that is quite difficult to capture (Herring et al, 2006). The use of the two corpora can also provide insights into differences in linguistic creativity in two discourse genres.

According to Lexis Nexis classification, 17 articles were published in newspapers (see Figure 3), 16 in Newswires \& Press Releases and other news sources and one in form of a blog.

[INSERT FIGURE 3 HERE]

In contrast, the web pages accessed by the WebCorp tool on 3 November 2008 returned a large number of blog articles. Out of a total of 84 concordances generated out of 147 webpages there were 54 blog webpages, although 6 pages were reproduced 5 times. Only two were published in 2007 , the rest in 2008 . This means that the two corpora complement each other nicely and cover the use of the compound 'carbon indulgence' world-wide in English speaking new media and blogs (as far as this is possible using such search tools as Lexis Nexis and WebCorp).

new carbon compounds are still being created all the time and we are monitoring their use in other climate debates. 
To understand the debate in the two corpora, it is necessary to provide some background information about the contested issue of carbon offsetting, a discursive context in which 'carbon indulgence' is embedded.

\section{Background}

The OED defines carbon offset as follows:

carbon offset $n$. an action or process (typically the planting of trees) which counteracts or is claimed to counteract the emission of carbon dioxide resulting from industrial or other human activity; a quantifiable amount of such action as a tradable commodity.

Some uses of the compound are listed from 1990 when it was reported that in 1989 "the first 'carbon offset' project was launched with considerable fanfare" (OED). Since then things have become more complicated. Carbon offsetting is in fact one of the most complex monetary mechanisms used in the fight against climate change. [wiki quote deleted]

It is interesting to note that in our linguistic carbon compounds (the emission of) 'dioxide' has become almost invisible through ellipsis (it is a so called incomplete compound). Other greenhouse gases have become even more sidelined in public discourse after the rise of carbon compounds to discursive prominence, despite the fact that they all contribute to climate change. As the webpage on carbon offsetting maintained by the Department for Environment, Farming and Rural Affairs points out: 
Greenhouse gases have a long life-span and tend to mix evenly in the atmosphere. It therefore does not matter where gases are emitted in the world the effect on climate change is the same. To compensate for unavoidable emissions equivalent emissions savings can be funded elsewhere, meaning that the overall effect is zero. This is called carbon offsetting.

Although it is not a cure for climate change, carbon offsetting is a useful means of helping to tackle it for several reasons:

Carbon offsetting involves measuring emissions from our own activities, helping to raise awareness of our impact. Combined with reducing our own emissions, carbon offsetting can directly address this impact.

When done in a robust and responsible way, carbon offsetting leads to a reduction in carbon dioxide emissions in the area local to the offsetting project, often in developing countries.

Carbon offsetting projects, such as those approved by the United Nations, provide a mechanism for investment in clean technology in the areas which lack it the most. Such investment can help encourage the spread of low-carbon development across entire regions, further reducing climate change impact. (Defra, 2009)

Such climate change mitigation schemes have, however, become rather contentious issues. The controversial aspects of carbon offsetting have most effectively been condensed into one compound, namely 'carbon indulgence', a compound used in what has also become known as the 'indulgence controversy', as some believe carbon offsets makes it easier for those who pollute to continue in their behaviour, but without feeling 
guilty. Wikipedia, with its ear to the ground of popular discourse has captured this in its article on carbon offsets.

Some activists disagree with the principle of carbon offsets, likening them to papal indulgences, a way for the guilty to pay for absolution rather than changing their behavior. For example, George Monbiot, an English environmentalist and writer, says that carbon offsets are an excuse for business as usual with regards to pollution. Proponents hold that the indulgence analogy is flawed because they claim carbon offsets actually reduce carbon emissions, changing the business as usual, and therefore address the root cause of climate change. (Wikipedia article, 3 November, 2008)

Our hypothesis was that the term 'indulgence' had been most prominently used by Monbiot in 2006 in a critique of carbon offsetting activities in an article for The Guardian, in a blog and in a book (Monbiot, 2006 a, b, c) . Monbiot compared offsetting schemes to the medieval practice of selling 'indulgences' or as the OED defines it:

'A remission of the punishment which is still due to sin after sacramental absolution, this remission being valid in the court of conscience and before God, and being made by an application of the treasure of the Church on the part of a lawful superior' (Amort, quoted in Catholic Dict. s.v.).

We shall come back to this definition later when analysing our corpora. Monbiot points out: 
Without requiring any social or political change, and at a tiny cost to the consumer, the problem of climate change is solved. Having handed over a few quid, we can all sleep easy again.

This is not the first time that such schemes have been sold. In his book The Rise of the Dutch Republic, published in 1855, John Lothrop Motley describes the means by which the people of the Netherlands in the 15th and 16th centuries could redeem their sins. "The sale of absolutions was the source of large fortunes to the priests. ... God's pardon for crimes already committed, or about to be committed, was advertised according to a graduated tariff. [...]" Just as in the 15th and 16th centuries you could sleep with your sister and kill and lie without fear of eternal damnation, today you can live exactly as you please as long as you give your ducats to one of the companies selling indulgences. It is pernicious and destructive nonsense. (Monbiot, 2006a)

Monbiot himself did not use the compound 'carbon indulgence'. However, when checking Lexis Nexis as well as the internet, we found that this compound had been in circulation since around the year 2000, but the medieval sense only came to prominence in 2006, and, it appears, relatively unrelated to Monbiot's discursive framing activities.

\section{Analysis}

There is only one reference to Monbiot in our corpora and this with respect to inspiring Carbon Rationing Action Groups or CRAGS in 2005 (see Nerlich and Koteyko, in press), not with reference to 'carbon indulgence' or indulgence. Instead, the trigger for the 'carbon indulgence' debate in our corpora seems to have been Al Gore's production of the film An Inconvenient Truth (2006). The popularity of this controversy is also 
indicated by creative plays on the film title, which produced new compounds, such as 'inconvenient talk' and 'inconvenient indulgence'.

In our corpora the main social environment or niche in which the compound evolved and to which it was adapted by writers was the release of the film followed by a critique of Gore's 'carbon-heavy' lifestyle. ${ }^{4}$ The film is an American documentary about global warming, presented by former United States Vice President Gore and directed by Davis Guggenheim. The film premiered at the 2006 Sundance Film Festival and opened in New York and Los Angeles on May 24, 2006. The film was released on DVD by Paramount Home Entertainment on November 21, 2006 (for more information on the film, see Al Gore's website: http://www.climatecrisis.net/). A companion book by Gore, An Inconvenient Truth: The Planetary Emergency of Global Warming and What We Can Do About It, reached number 1 on the paperback nonfiction New York Times bestseller list on July 2, 2006 (New York Times, 2006). In February 2007 Gore was accused of hypocrisy, as it was revealed that energy consumption at his mansion was quite huge. In October 2007 Gore and the UN's Intergovernmental Panel on Climate Change won the Nobel Peace Prize.

We shall first provide an overview of some of the main arguments around carbon offsetting condensed through the lens 'carbon indulgences', then look more closely at the variety of compound life forms in the two corpora and their preferred discursive niches, before analysing their use in various 'discourse formations'.

One has to keep in mind that 'carbon indulgence' can have two meanings. One sense refers metaphorically to 'medieval indulgence', as described above. Here 'carbon

\footnotetext{
${ }^{4}$ This might be an artefact of the fact that a large majority of article collected by Lexis Nexis under 'All English Language News' originate from the US.
} 
indulgence' is definitely a metaphor. The other sense refers metonymically to selfindulgent or over-indulgent actions that result in an increase in carbon emissions, that is, to " $[\mathrm{t}]$ he action of indulging (desire, inclination, etc.); the yielding to or gratification of some propensity (const. of, in, formerly to); the action of indulging in some practice, luxury, etc." (OED). However, the metonymy goes further, insofar as 'carbon indulgence' generally refers to the action of 'neutralising' this self-indulgence through the purchase of carbon offsetting products. At the end of this chain of inferences it has come to mean 'carbon offset' itself, for which it is often used as a synonym. 'Carbon indulgence' is therefore an ambiguous compound, that is, it has at least two, partly overlapping, meanings. One or the other meaning can be highlighted in its use in a particular discourse or they can be pitted against each other. As will become clear below, 'carbon indulgence' in the medieval sense has now become a quasi-synonym of 'carbon offset'.

\subsection{English speaking news}

The first article to use 'carbon indulgence' appeared in The Economist on 25 March, 2000 entitled 'Cultivating carbon'. It advocated trapping greenhouse gases in plants to mitigate climate change, but to do so indirectly through the market mechanisms of carbon offsetting and carbon credits:

The best way to encourage such practices is to get someone else to bear the cost. One idea is to persuade greenhouse-gas producers to offset their emissions by paying farmers to sequester carbon for them, creating a market to allow buyers and sellers to trade in such carbon indulgences. 
The second article to use the compound appeared some years later on 8 August 2006 in The New York Times and switched the focus from the market to religion. It was entitled "Sinful Second Homes". The article refers to another compound 'carbon footprint' which, it says is "a concept you may have learned from Al Gore" and creatively modifies this compound by pointing out that Gore's carbon footprint is more like a "Godzilla-sized carbon footprint". It should be pointed out however that 'carbon footprint' has been in use since 1999 (OED).

Our initial hypothesis was that Monbiot had introduced the metaphorical framing of carbon offsetting as a medieval indulgence. However, it seems that Charles Komanoff, an economic consultant to environmental groups, had used this framing first. According to John Tierney, the author of the New York Times article (published a few months before Monbiot published his article in the Guardian),

He argues in Grist, an environmental magazine, that paying a penny or so per mile to offset the carbon from driving your car isn't the moral equivalent of riding your bike instead. It's more like the Catholic Church's old system of selling indulgences so the rich could avoid something scarier than global warming: purgatory. [...] Komanoff says his fellow environmentalists should stop offering "get out of purgatory free" cards to the rich and instead insist that everyone personally reduce energy use.

I'm not such a purist myself -- I'd let the average person salve his conscience with a carbon indulgence. But I'd hold environmentalist preachers like Gore to higher standards, especially when they're engaging in unnecessary energy use. 
This then seems to be the first time that 'carbon indulgence' was used in its religious sense and immediately embedded in a wider semantic field or niche of words and concepts with religious meaning. We shall explore this discursive niche a bit further below.

However, there are two articles which go further and really engage with the topic of carbon 'indulgence' schemes from a point of view of an environmental critic on the one hand, an economist on the other. Both are sceptical of the benefit of such schemes. The first is the reproduction of a blog entitled 'Carbon offsets are less like indulgences and more like tithes' (originally published here:

http://stevejanke.com/archives/228530.php). The blogger, interestingly, uses carbon indulgence in two senses at once, saying: "Hallelujah! They're back selling selfindulgences". Mustering a lot of historical and religious knowledge (which is more briefly encapsulated in the definition of indulgence taken from the OED, above), he points out that:

You can't be granted an indulgence for a sin you are about to commit. You can't even be granted an indulgence for a sin that has been committed until you have earned forgiveness for that sin.

Rather, he argues, carbon offsetting is a case "of a government collecting taxes on behalf of what amounts to a faith. That is not an indulgence, but a tithe". The argument he makes is against 'the Church of Green' who want to bring us back to the Middle Ages by making an as yet voluntary payment obligatory and, he says, "the Greens will have succeeded at wrecking our economies" and "we'll be forced to pay them for the privilege of letting them do it." This critical stance is also exemplified by a news item that reports 
that an institute that despises environmental regulation "handed out a goody bag that included a satirical 'carbon indulgence' coupon" (this was also discussed in the blogs).

Another long article dealing with carbon offsetting from the point of view of the economy and regulation, the longest in the corpus (written for Reason Magazine by Ronald Bailey on 3 September 2008), summarises the development and regulation of capand-trade schemes for American business readers. It introduces an image related to carbon indulgence that is quite unique under the section heading "Baptists and Bootleggers" - or 'climate prophets' and 'climate profiteers'.

The idea of a Baptist and Bootlegger coalition is that both Baptists and bootleggers support blue laws forbidding the sale of liquor, according to Clemson University economist Bruce Yandle. The Baptists favor blue laws because they are against sin and the bootleggers because they create a profitable black market for them. In this case, the righteous environmentalists denounce emitting carbon as a climate sin while wily corporate bootleggers think they can grow rich trading scarce carbon indulgences, a.k.a emissions allowances.

Another news article is equally scathing and cynical using the word scam which was also used in our corpora to extend the original carbon compound to 'carbon indulgence scam' (see next section):

If it's true that every noble cause starts out as a crusade, turns into a business, and ends up as a scam, it can be said the industry of buying and selling guiltreducing carbon indulgences has transitioned its way through the stages of the aphorism in near-record time. 
As one can see, the carbon offset critics who discuss carbon indulgences in the Lexis Nexis corpus are quite creative in their arguments against such schemes. However, this creativity does not extend to the compounds themselves. This is quite different in the corpus of blogs, where similar arguments are rehearsed but where more linguistic creativity around compounds is displayed.

\subsection{Creative compounds in blogs}

As also found when comparing newspaper reports with blogs relating to synthetic biology (Hellsten and Nerlich, in prep.), blogs seem to provide a niche for creative language use, perhaps because bloggers feel less constrained by both journalistic and linguistic norms. Bloggers debating carbon offsetting especially engaged in inventing a variety of longer compounds. That is to say the two-word compound 'carbon indulgence' has become productive in so-called 3-grams or three-word units (not to be confused with triplets of sequentially contiguous amino acids in the jargon of biochemistry!); some have even grown into 4-grams or 5-grams. Examples of 3-grams are: 'carbon indulgence market', '(modern-day) carbon indulgence scheme', 'carbon indulgence money’, 'carbon indulgence purchase', 'carbon indulgence dealer' (with reference to Gore), 'carbon indulgence companies' (with reference to Gore), 'carbon indulgence fees', 'carbon indulgence sites', 'carbon indulgence coupon', 'carbon indulgence craze', 'carbon indulgence hypocrisy', 'carbon indulgence scam' and 'carbon indulgence peddlar'.

The compound heads of the first ten examples belong to the semantic set of 'finance' and are further testimony to the proliferation of the 'finance carbon compounds cluster' mentioned above. The rest of the compounds are headed by highly attitudinal lexis used to express criticism of carbon offsetting. A similar tendency can be observed in 
larger units. Examples of 4-grams are 'carbon indulgence sales business' and the wonderful '(magic) carbon indulgence pixie dust'. There are two 5-grams: 'carbon indulgence omnibus conglomerate' and 'travelling carbon indulgence circus' (with reference to Gore), where the compound is embedded into 'travelling circus'.

The synonymy between indulgence and offset is highlighted in the quasitautological 'carbon indulgence offsets' and 'carbon indulgence style offsets' and in fake 'repairs', such as "as long as you purchase a carbon indulgence - oops carbon offset", a rephrasing that was mirrored in the Lexis Nexis corpus by "we can purchase carbon indulgences - em, credits".

This shows that, compared to more traditional media, blogs seem to provide a niche for linguistic creativity, especially when it comes to criticising carbon off-setting schemes, which are generally framed as a scam. This is most apparent in the 4-gram which merges two creative compounds, namely 'carbon indulgence' and 'pixie dust'. As we all know, pixie dust was used by Tinkerbell in Peter Pan and, when sprinkled over humans, allowed them to fly. Here it is used ironically to indicate that carbon offsetting will not solve all the problems of climate change.

More so than in the newspapers, carbon compounds in blogs also tend to be used in dense networks of other creative combinations involving the word carbon. Thus a blog webpage that came up in the WebCorp search as containing the compound 'carbon indulgence' usually contained a number of other carbon compounds which were used to structure the whole argument. For example, the bloggers on this page (http://pajamasmedia.com/richardfernandez/2008/07/07/money-money-

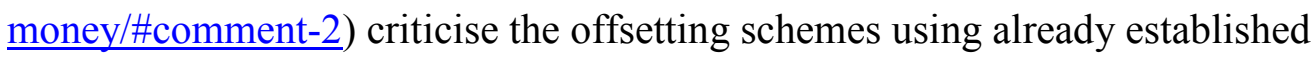
compounds such as 'carbon credit' and more 'ad hoc' ones such as 'carbon ration cards': 
Recently, environmental activists in Britain have tried to create a form of carbon money which will effectively determine how ordinary people can spend what they earn.

And not only will polluting corporations seek to buy "carbon credits" to avoid upgrading their facilities and actually clean the air, but an entire economy will appear based upon fraudulent reporting of carbon footprints.

A criminal mind couldn't concoct a more efficient system for graft than the carbon indulgence. The "carbon credit" looks like "No Child Left Behind" as applied to the atmosphere and is likely to have similarly dismal results.

On this particular blog, the carbon compounds, including 'carbon indulgence' together with other surrounding compounds, help to furnish two main arguments 1) that carbon offsetting does not work because it does not prevent bad behaviour in the first place ('polluting corporations' not cleaning the air) 2) that the economic part of carbon offsetting is problematic because offsetting schemes can be exploited for personal and company's enrichment through 'fraudulent reporting of carbon footprints'.

\subsection{Semantic fields}

So far we have studied the compound 'carbon indulgence' and its 'off-spring' in its immediate discursive contexts. Another way to study its meaning and use is to explore the semantic field (a grouping of words which are associated or which define each other) in which it is embedded. It seems that in both corpora 'carbon indulgence' is predominantly used in the semantic field of religious discourse, tightly linked to the definition of carbon indulgence as the full or partial remission of temporal punishment due for sins which 
have already been forgiven at confession. This sets the compound up for uses together with other words and phrases such as '(green) guilt', 'guilt-reducing carbon indulgences', 'assuage the pangs of carbon-riddled guilt', 'absolve the agency of its environmental sins', 'thou shalt not emit', 'high-carbon sinners', 'environmental soul-cleansing', 'going to confession', 'conscience free answer', 'clean carbon conscience', 'reward our virtue', 'a long penance', 'wipe out our sins', and so on. Some articles and blogs expand outwards from this more restricted field around indulgence towards talking about environmentalism as a religion (with reference to Gore), the 'Church of Green', environmental preachers and Gore as the $\mathrm{CO}_{2}$ pope.

Two events reported in the Lexis Nexis corpus add real-world padding to this tightly organised religious discourse niche around carbon indulgences. One article entitled "Carbon indulgences" reports that

The carbon offsets market just received the blessing of His Holiness Pope Benedict XVI. The Vatican has recently announced it will become the world's first carbon-neutral sovereign state by creating a forest preserve in Europe. (Carbon Control News, 16 July, 2007)

The other article is entitled "British Bishops Launch Carbon Fast" ('carbon fast' is, by the way, one example of what we have called 'episodic' compounds linked to the 'carbon diet' discourse). It reports that the bishops of London and Liverpool have suggested that instead of chocolate, "[ $[\mathrm{t}]$ his Lent, one could give up plastic bags or incandescent bulbs or any other carbon indulgence you could think of" (National Public Radio, transcript, 7 February, 2008). Here the religious frame is activated but the compound is used in its meaning of luxury or self-indulgence. 
To summarise, the compound 'carbon indulgence' is, it seems, embedded in two types of linguistic fields, frames or ecologies, one stretching over the various conceptual aspects of carbon finance (carbon market, credit, neutral and so on), the other stretching over the various conceptual aspects of sinning and guilt. These two fields are metaphorically linked by the fact that indulgences in the sense of self-indulging in a luxury can be said to be a sin, metaphorically speaking.

Overall then it seems that while moral and religious framing is used to tell people that they ought to reduce their carbon emissions (unless they want to become 'carbon sinners'), the carbon indulgence controversy critically challenges this prevailing framing by exposing some of its pitfalls in a context where moral guilt can be alleviated through what seem to be ethically and environmentally dubious financial mechanisms.

\subsection{Compounding as an aid to argumentation}

However, the meanings of 'carbon indulgence' compounds are not only deployed in the semantic fields discussed above. It is also possible, particularly in English, to embed a word or word combination into another structure and create a complex hybrid (aka compound) consisting of words belonging to different and diverse semantic sets. This process is particularly well illustrated by our carbon compounds, as we have seen in the examples of 3, 4-, and 5-grams created around 'carbon indulgence' in blogs. By adding such words as 'craze', 'hypocrisy' etc. to the existing compound 'carbon indulgence' members of a speech community are able to express their evaluation of a particular aspect of the ongoing climate change mitigation debate in a compact way. Moreover, communicating a message in the form of (especially longer) compounds may also serve the additional purpose of drawing attention to the message with the help of a creative/playful word formation and making a certain type of discourse, especially it 
seems the critical one, more salient. We have already seen this in the example with 'pixie dust'. Another example of this type of use of a compound can be found in a spoof on Gore's Nobel Acceptance speech in one of the blogs (http://moxargongroup.blogspot.com/2007/10/not-very-nobel-prize.html):

Let's face it, that is the real reason I got this award. It can't be for my 'charitable work' which is neither charitable and it only works to make me millions of dollars. I mean come-on, my little carbon indulgence scam is like a drunk driver tearing down a street who says it's okay because he tossed some money as he passed an AA meeting.

Here 'carbon indulgence' is not only part of an extended critical compound put also part of a vivid extended metaphor that turns a scam into a drunk driver absolving his or her conscience in a clearly silly way.

\subsection{Discourse formations}

Overall the debate about carbon indulgences in our corpora tends to denigrate carbon offsetting schemes as a cynical exploitation of people's feelings of guilt in the context of climate change, a guilt that can be related to moral or dietary sins or both.

However, one can also observe the emergence of four distinct clusters or discourse formations around 'carbon indulgence' as the rhetorical hub. The first and 'primary' discourse formation of what we call environmental offsetting sceptics has evolved around the use of 'carbon indulgence' in the sense intended by Monbiot when he talked about medieval 'indulgences'. According to this discourse formation, carbon 
offsetting schemes do not work because they resemble medieval indulgences that absolve you from sinful behaviour but do not prevent sinful behaviour in the first place.

As the debate around economic and social implications of climate change mitigation progressed in time and Internet space, three other related but at the same time distinct discourse formations seem to have emerged. Although related to environmental offsetting sceptics in terms of their focus on the criticism of offsetting, economic offsetting sceptics point out the rather cynical exploitation of carbon offsetting/indulgence schemes for the purpose of personal enrichment rather than as a means to mitigate climate change, sometimes also referring to a potential spread of corruption or fraud.

There are also climate change sceptics who fear the 'church of green' and argue that carbon indulgences in the medieval sense are actually tithes or taxes that will drag us economically back to the Middle Ages.

And finally there are what one might call Al Gore sceptics, that is people who accuse Gore's campaign of climate change education of hypocrisy and vain-glory, especially when constructing Gore's own energy behaviour as over-indulgent. This discourse formation is closely linked to the climate change sceptics who see carbon offsetting as a corrupt practice similar to the indulgences sold by the Catholic Church.

It is interesting to note that at least the last three discourses seem to have been prompted by the environmental trigger of the $\mathrm{Al}$ Gore phenomenon in the US which then launched 'carbon indulgence' on an evolutionary rhetorical path which it might not have taken had Gore never released his film.

\section{Conclusion}

In our introduction we claimed that the collective use of carbon compounds worked in ways that are similar to the invisible hand process. This process tries to explain complex 
collective behaviours or structures that emerge from the interaction between individuals and their environments. We also argued that the emergence and spread of carbon compounds was in a certain way the result of collective linguistic creativity within the constraints of certain ecological conditions, both real and metaphorical.

The study of framing devices such as compounds, which seem to work as nodes for different arguments, can help us establish a clearer picture of how collaborative content and argument creation works in practice, especially with relation to climate change. If we conceptualise carbon compounds, such as 'carbon indulgence', as organisms, we have seen how they adapt (or rather are adapted by their users) to various argumentative purposes and discursive formations/niches, how they change, both lexically and figuratively in shape and in meaning over time and over discourse formations, depending on which communication channel is used (traditional media, blogs etc.). Carbon compounds can therefore be used as indicators for observing how human symbolic cultures change and adapt in response to environmental threats, how symbolic innovation and transmission occurs. These symbolic changes are however not 'only symbolic', they are indicators of trends in human thinking and behaving towards climate change. In this case we have observed a trend towards denying the usefulness of certain financial climate change mitigation mechanisms which might lead to what can be called 'carbon offsetting' apathy or cynicism.

The creation and use of carbon compounds provides a window of opportunity to study one of the mechanisms underlying the framing of climate change by various stakeholders. Until now, research has mostly focused on the study of climate change arguments deduced from a collection of texts (Ereaut and Segnit, 2006; Weingart et al. 2002). Such texts are essentially a collection of opinions on a number of points with regard to different aspects of climate change mitigation and any thematic or content 
analysis study is therefore likely to overlook this complexity. In contrast, the study of compounds allows tracing the same stock of expressions containing the word 'carbon' and then studying the types of arguments they 1) were initially created for and 2) are used for in different time periods and by different groups. Such a focus on specific words as nodes or hubs of different arguments may go some way towards illuminating the complexity of such a multifaceted problem as climate change.

At the beginning of this article we referred to the Cambrian explosion to frame our fascination with the explosion of carbon compounds. We shall end with another analogy used by linguist and compounding expert Antoinette Renouf:

Indulging in hyperbole for an instance, this [the use of compounds] is evidence of the marvellous self-generating and self-renewing power of language, words like stars soaring into the linguistic firmament in a blaze of popularity, spinning other words off hither and thither, and at length tumbling back down into the calm(er) reaches of servitude. (Renouf, 2007, p. 87).

In both modes of being, as fireworks or ashes of linguistic activity, carbon compounds structure our thinking and talking with relation to climate change. They have conceptual and possibly behavioural implications that need further research.

\section{References}

Aitchison, J. (1993). Words in the Mind: An Introduction to the Mental Lexicon. Oxford: Blackwell.

Alexander, R. (2008). Framing discourse on the environment. London: Routledge. 
Boykoff, M. T. (2008). Media and scientific communication: A case of climate change. Geological Society 305, 11-18.

Carvalho, A. (2007). Ideological cultures and media discourses on scientific knowledge: re-reading news on climate change. Public Understanding of Science, 16 ( 2),223-243. Cook, G. (2004). Genetically Modified Language: The Discourse of Arguments for GM Crops and Food. London: Routledge.

Defra (2009). Carbon offsetting - an introduction. Available at: http://www.defra.gov.uk/ENVIRONMENT/climatechange/uk/carbonoffset/intro.htm Ereaut, G. and Segnit, N. (2006). Warm Words: How We Are Telling the Climate Story and Can We Tell It Better? London: Institute for Public Policy Research. Fill, A. and Mühlhäusler, P. (2001). The Ecolinguistics Reader. London: Continuum. Gerbig, A. (1996). Sprachliche Konstruktion politischer Realität: stilistische Variation in der Ozondebatte. In Fill, A. (ed.). Sprachökologie und Ökolinguistik. Tübingen: Narr, pp. 175-186.

Hellsten, I . (2003). Focus On Metaphors: The Case Of "Frankenfood" On The Web. Journal of Computer-Mediated Communication, 8(4).

Hellsten, I. and Nerlich, B. (in prep.). Science communication in the age of the web. The case of synthetic biology.

Heringer, H. (1984). Wortbildung: Sinn aus dem Chaos. Deutsche Sprache, 12,1-13. Herring, S. C., Scheidt, L. A., Bonus, S., and Wright, E. (2004). Bridging the gap: A genre analysis of weblogs. Proceedings of the Thirty-seventh Hawaii International Conference on System Sciences (HICSS-37). Los Alamitos, CA: IEEE Press. Hulme, M. (2008a). Amid the financial storm: redirecting climate change: http://www.opendemocracy.net/article/amid-the-financial-storm-redirecting-climatechange (accessed 12 December, 2008). 
Hulme, M. (2008b). Why We Disagree About Climate Change: Understanding Controversy, Inaction and Opportunity. Cambridge: Cambridge University Press.

Keller, R. (1989). Invisible-hand theory and language evolution. Lingua, 77, 113-27.

Klemperer, V. (1947). LTI [Lingua tertii imperii]. Notizbuch eines Philologen. Stuttgart:

Reclam, 2007.

Lemke, J. (1990). Talking Science. Language, Learning and Values. Westport, CT:

Greenwood.

Meyer, R. (1993). Compound Comprehension in Isolation and in Context: The

Contribution of Conceptual and Discourse Knowledge to the Comprehension of German Novel Noun-Noun Compounds. Tübingen: Niemeyer.

Monbiot, G. (2006a, 19 October). Selling Indulgences. Retrieved 10 December, 2008 from http://www.monbiot.com/archives/2006/10/19/selling-indulgences/.

Monbiot, G. (2006b). Paying for our sins. Guardian, 16 October.

Monbiot, G. (2006c) Heat: How to Stop the Planet Burning. Allen Lane, Penguin Press. Munat, J. (2007). Lexical creativity as a marker of style in science fiction and children's literature. In J. Munat (ed.) Lexical Creativity, Texts and Contexts. Amsterdam: John Benjamins Publishing Company, pp. 163-185.

Nerlich, B. and Koteyko, N. (in press). Carbon reduction activism in the UK:

Lexical creativity and lexical framing in the context of climate change. Environmental Communication.

New York Times (2006). Paperback nonfiction bestseller list: http://www.nytimes.com/2006/07/02/books/bestseller/0702bestpapernonfiction.html?scp $=2 \&$ sq $=$ inconvenient $\% 20$ truth $\% 20$ bestseller $\% 20$ july $\% 202006 \&$ st $=$ cse $($ accessed 25 February, 2009).

Oxford English Dictionary (online): www.oed.com/ 
Renouf, A. (2007). Tracing lexical productivity and creativity in the British media: The Chavs and the Chav-nots. In J. Munat (ed.) Lexical Creativity, Texts and Contexts. Amsterdam: John Benjamins Publishing Company, pp. 61-89.

Sinha, C. (2006). Epigenetics, semiotics and the mysteries of the organism. Biological Theory 1 (2): 112-115.

Turney, J. (1998). Frankenstein's Footsteps. New Haven \& London: Yale University Press.

Warren, B. (1978). Semantic Patterns of Noun-Noun Compounds. Acta Universitatis Gothoburgensis, Goteborg, Sweden.

Weingart, P., Engels, A., Pansegrau, P. (2000). Risks of communication: Discourses on climate change in science, politics, and the mass media. Public Understanding of Science, $9(3), 261-283$.

Zawada, B. (2006). Linguistic creativity from a cognitive perspective. Southern African Linguistics and Applied Language Studies, 24(2), 235-254(20). 